\title{
Tall Papillae Present
}

National Cancer Institute

\section{Source}

National Cancer Institute. Tall Papillae Present. NCI Thesaurus. Code C95511.

A morphologic architectural pattern indicating the presence of tall papillary structures. 